\title{
Distance Online Learning and Evaluation Framework
}

\author{
C. Snae, M. Brueckner, and E. Hirata
}

\begin{abstract}
In this paper, the authors present the concept of a system for Distance Object Learning and Evaluation (DOLE), which can be used during the teaching-learning process as a virtual learning environment. The term Distance Object Learning is used here for learning over a computer network or the Internet about real world entities that are distinguishable from others. The DOLE system concept uses standards for Learning Object Metadata (LOM) at different levels of abstraction. The objective of the resulting system is not only the correct and retrievable description of the course material covered by the LOM but also the further use of parts of the LOM data set for the generation of learning materials and students' learning development assessment, which can be represented by quizzes and tests. The Distance Object Learning and Evaluation system concept outlined in this paper is based in part on an earlier version of an E-learning Assessment System for Young learners (EASY). DOLE extends the concept of EASY by a learning component and by posing system generated questions with the help of a forward-chaining inference engine to find out about a specific item (object) of the domain of instruction. As the questioning process is bidirectional ("open" questions can be asked by the system as well as by the learner), DOLE is more targeted at advanced and adult learners than at young learners. The ultimate goal is to use the DOLE system concept as a part of a virtual college or university.
\end{abstract}

Index Terms-Distance learning, e-assessment, young learner, rule-based system.

\section{INTRODUCTION}

L ESSON in the teaching-learning process for distance learning [1] are typically designed to help students to find essential information or to carry out desired tasks, e. g. as assignments. As information related instruction conveys information about the domain of instruction there is no specific skill to be learned during that process; for example, in this part of the course the appearance of an object can be described. The lessons for performance-based instruction on the other hand, aim at resulting in improved procedural skills, which the students are expected to train or work out during the teaching-learning process [2].

Manuscript received May 29, 2008. Manuscript accepted for publication October 28, 2008.

C. Snae is with the Naresuan University, Phitsanulok, 65000 THAILAND (phone: +66-81-4755113; fax: +66 55 261025; e-mail: chakkrits@nu.ac.th).

M. Brueckner is with Naresuan University, Phitsanulok, 65000 THAILAND (phone: +66-89-4616110; fax: +66 55 261025; e-mail: michaelb@nu.ac.th).

E. Hirata is with the Department of English, University of Birmingham, Birmingham, (e-mail: exh411@bham.ac.uk).
To find out how much and how well students have learned the material a number of formal and informal tools and methods are used. For example, to formally evaluate student learning, most teachers use quizzes, tests, examinations, and homework, which help to assess the student's level of knowledge and to assign marks and grades.

A number of different techniques are used to assess learning informally, such as teachers listening to students' remarks and questions, teachers posing questions, and observing body language and facial expressions. With these informal assessments the teachers are able to adjust their teaching better to the students' needs. Slowing down the pace of instruction or reviewing specific material of the teachinglearning process as a response to students' demands can increase the learners' motivation and learning outcome.

The distance learning-teaching process is somewhat different to classroom teaching-learning process [3]; there are no:

- traditional, familiar classrooms,

- more or less homogeneous groups of students,

- students' questions, comments, signs of body language, and facial expressions, which the teacher can observe face-to-face,

- ways to control the distance delivery system completely,

- spontaneous ways to talk to students individually.

For these reasons, distance instructors may find it appropriate to extend the formal evaluation process of the students by testing and homework through using a more informal approach in collecting data to determine:

- student comfort with the method used to deliver the distant instruction,

- appropriateness of assignments,

- clarity of course content,

- how well class time is being spent,

- teaching effectiveness,

- the ways to improve a course,

- other types of evaluation.

Evaluation can be either formative, summative, or a combination of both [4]. Relevant data are collected for quantitative and qualitative analysis.

The formative evaluation:

- is an on-going process to be considered at all stages of instruction.

- enables instructors to improve the course as they proceed. 
- facilitates the adjustment of course management and materials.

- identifies gaps in the instructional plan or the need for more adjustments.

Among the strategies used by instructors to collect formative data from their distant students are e-mail, online chat, and phone calls.

E-mail (electronic mail) is an asynchronous way of communication and can be very effective for instructors and students to communicate. Instructors can elicit and extend material covered in the online course, and students can ask questions or giving comments.

Online chat is a synchronous communication method and can also be very effective in gathering informal data about students' learning achievement and motivation. As we observe that almost all students use online chat for communication, this method can be seen as a non-interrupting way to communicate with students.

Teachers should call students often and ask them open ended questions to let students voice their concerns. Follow with probes (e.g., "Then, will you need more information sources?"). Set phone-in office hours but be sure to welcome calls at other times.

The summative evaluation:

- helps to evaluate the overall effectiveness of the finished course and instructional material,

- can be a basis for developing a revision plan,

- can be a baseline of information for designing a new plan, program, or course,

- does not help current students since can attend only after having completed the course.

Quantitative evaluation uses statistical methods and can evaluate data about large groups of people; under some circumstances, a considerable number of data is needed to come to statistically relevant results. Unfortunately, most of the classes in distance learning courses are small, so that they defy statistical analysis.

By definition and design, forced choice surveys offer respondents a limited number of possible response options. Therefore, new insights and novel perspectives that are not inside the provided response set will not be reported.

The often tedious nature of quantitative data collection can discourage formative evaluation, and leads to an over-reliance on summative evaluation.

Qualitative evaluation uses a wider range of information, which can be very specific und inhomogeneous, so the categorization of the data can be cumbersome. Qualitative evaluation does not depend so much on the size of the classes; small classes are generally not problematic for getting useful results [5].

For qualitative evaluation there are many different methods of data collection available, such as open ended questioning (e. g. respondents are asked to specify strengths and weaknesses of a course and suggest modifications), participant observation and non-participant observation (with the instructor participating or not participating in class and observing group dynamics and behavior), content analysis (the evaluator using predetermined criteria to review course documents including the syllabus and instructional materials as well as student assignments and course-related planning documents), and interviews (with a facilitator or specially trained person gathering data through one-on-one and smallgroup interviews with students).

Quantitative and qualitative evaluation can be used in various areas of the teaching-learning process and learning environment. Examples are:

- Course content (relevancy, organization of the materials, adequate body of knowledge);

- Class formats (effectiveness of the lectures, appropriateness of the lab assignments);

- Use of technology (attitudes towards technology, familiarity with technology);

- Class atmosphere (conduciveness to student learning)

- Assignments (adequate level of difficulty, usefulness, timeliness of feedback, time required for finishing);

- Tests (frequency, relevancy, sufficient review, difficulty, feedback);

- Support services (facilitator, technology, library services, instructor availability);

- Student achievement (adequacy, appropriateness, timeliness, student involvement);

- Student attitude (attendance, assignments submitted, class participation);

- Instructor (contribution as discussion leader, effectiveness, organization, preparation, enthusiasm, openness to student views).

There are also approaches, which can be seen as mixed methods circumventing some of the drawbacks of the pure quantitative and pure qualitative approach. These approaches are mainly used outside the educational environment, such as evaluating socio-economic programs and universities [6].

Much effort has been spent for the technical reuse of electronically-based distance teaching materials and in particular creating or re-using Learning Objects [7]. Learning objects (LO) are teaching units that are properly indexed (tagged) with keywords, and maybe more metadata. LOs are often stored in as XML files, which enable better indexing and organizing structures. Creating a course requires putting together a sequence of LOs [8].

A common standard format for e-learning content is SCORM [9] whilst other specifications allow for the transporting of "learning objects" (Schools Interoperability Framework) or categorizing meta-data (LOM, [10]).

In this paper, we propose a framework for distance learning and evaluation framework for Thai language. In Sect. 2 the distance learning and distance assessment processes as they are seen in this research are described in more detail. The DOLE framework is presented in Sect. 3 together with some remarks on implementation details. In the final section we draw conclusions of this research and outline further work. 


\section{DistancE LEARNING AND AsSESSMENT}

While distance learning primarily refers to remote computer-enhanced education it is currently extending to emerging technologies, such as mobile computing (Mlearning) and Personal Digital Assistants (PDAs). Distance learning may include the use of web-based technologies, including blogs, polls (electronic voting systems), simulations, games, and wikis. The differentiation to blended learning is floating.

E-learning systems are mostly used together with face-toface learning, but they may be applied to distance learning after some adaptation. For a differentiation between face-toface and E-learning, see Fig. 1, which shows the portion of elearning in each of the teaching-learning models [11].

Distance learning has proven to be useful in tertiary education, e.g. universities, and in environments which need their learners to be lifelong learners. Contents of distance Elearning range from technical and medical knowledge to soft skills, such as social behavior. Even the instruction of handson practical work can be assisted by distance learning units.

Distance E-learning has to serve very different learner groups. There are novice learners, intermediate and advanced up to experienced students. Furthermore distance E-learning courses can be attended by dependent or independent learners who study full-time or part-time. Distance E-learning is based on prerequisites, such as management, culture, and IT [12]. Distance E-learning can be presented in many forms (see Table I).

All of these forms can be enhanced by multimedia content, which is designed to suit for various types of learners. Such multimedia materials can consist of:

- e-books,

- e-libraries, where we can borrow books online and check availability of books,

- streaming videos or audio files, where details and information are kept in multimedia files or sound and can be accessed via the Internet.

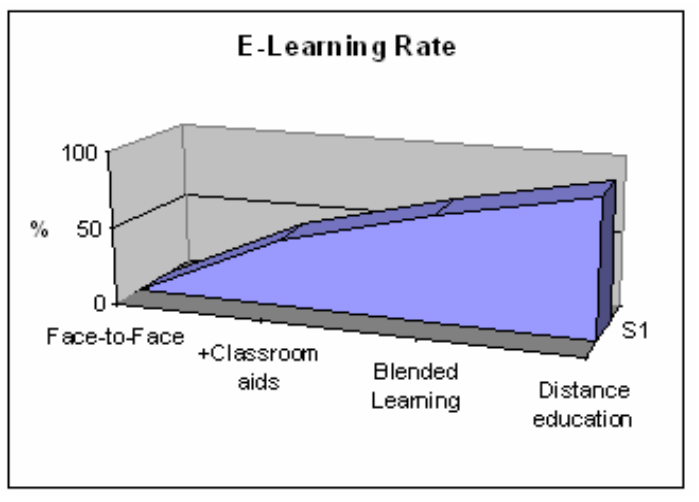

Fig 1. E-Learning rate in different learning environments.
TABLE I

FORMS OF DISTANCE E-LEARNING

\begin{tabular}{|l|l|}
\hline $\begin{array}{l}\text { Computer Based Training } \\
\text { (CBT) }\end{array}$ & $\begin{array}{l}\text { students learn by executing special training } \\
\text { programs on a computer }\end{array}$ \\
\hline Web Based Training (WBT) & $\begin{array}{l}\text { students learn by executing special training } \\
\text { programs on a computer via the Internet }\end{array}$ \\
\hline Blended Learning & $\begin{array}{l}\text { provision or use of resources which combine } \\
\text { e-learning (electronic) or m-learning } \\
\text { (mobile) with other educational resources }\end{array}$ \\
\hline Virtual Classroom, Lab & $\begin{array}{l}\text { Students study at home and use Voice over } \\
\text { IP and webcams in a virtual class, e.g. } \\
\text { performing experiments }\end{array}$ \\
\hline Digital Learning Games & $\begin{array}{l}\text { Computer games with an educational } \\
\text { background }\end{array}$ \\
\hline
\end{tabular}

Distance E-learning can meet diverse user needs and requirements and can be consumed just in time at home, on travel or at the working place. It can be designed for the user's context in small parts of the learning content. The content can be made available to a large number of participants. Participants can work out the material self-paced. So, maximum information retention is more likely. As learners study in their natural environments travel costs and associated expenses are considerably reduced.

Application in distance learning is a developing area and can often be seen in first language education and mostly English as a foreign/second language (EFL/ESL) situation. For instance, in the research into computer assisted language learning (CALL), the effectiveness of teaching vocabulary has been reported [13]. The importance of vocabulary knowledge is prominent in understanding any language (e.g. Wilkins, 1972). In the EFL (English as a foreign language) environment in particular, learning is generally more challenging. This is because there is little mental lexicon readily available to the learners at the early stage of learning. For instance, when learners are learning objects (such as fruits, vegetables) it is hard for learners to relate them with their meaning and their existing knowledge if they had not encountered them in their real life. Moreover, in teaching young learners in general, motivation is one of the important factors to consider since they tend to be less intrinsically driven compared to adult learners.

The framework for the learning process is considered by suggesting three steps: presentation, practice and performance. Having the available systems which are targeted to learners, however, they seem to lack the attention to the evaluation stage. In the case of evaluating learners, it is often neglected or the concept of 'assessing' learners being avoided for such reasons as the result could discourage learners, in case of them receiving negative results. However, it is important to consider the way to evaluate and check the understanding of the learners in any learning. It is necessary to have an evaluation stage, after any teachings and techniques used, so that it enables educators to monitor the learners' 
understanding as well as the effectiveness of the techniques and approaches, which in the end, also serve as a follow-up and feed into a revision phase. The points raised above (i.e. the motivation and learning environment factors) should be fed into the design of the interface for the assessment, which will be discussed in the next section.

\section{SYSTEM CONCEPT}

Nowadays, user interfaces can be designed and implemented with a wealth of technical opportunities, which may lead to overshadow the important points. For distance learners, the user interface must be playful and more attractive than that for adult learners, without distracting the users from the intended conversation [14], [15].

The learning design strategy has to take into account the learners' specific behavior and cultural background. In case of Thai students, for instance, there is a great demand of multimedia content, which has to add some fun to the learning materials. From our teaching experience Thai students tend to be social learners studying in groups and comprehend through visual stimuli as well as examples and case studies.

Numerous qualitative and quantitative studies are available that analyze the usefulness of applying computer games for instruction purposes. They are mainly driven by the question as to how acquire and improve the necessary skills that people will face in the 21st century: managing information, being adaptive to changing roles and environments.

Recent interest in games and learning stems from some complex debates about the very role and practices of education in a new century, rather than just from a simple belief that young people find games motivating and fun and, therefore, that they should be exploited in educational contexts. These debates suggest, among other things, that computer games are designed 'to be learned' and therefore provide models of good learning practices, and that by playing games young people are developing practical competencies and learning skills.

Interesting application areas for computer games are the development of strategic and logical thinking as well as language. That means, students are expected to develop their hard skills as well as their soft skills. Even the assessment of students can be made within the gaming environment as long as the boundary conditions are the same for every participant Prensky [16] suggests that today's learners have changed, and that video (and computer) game players are developing skills and competencies that others are not learning, such as decision making, data handling, multi-tasking, and information processing.

Characteristics of good instructional computer games include challenge and adaptability, a more practice-based rather than a didactic approach with authentic tasks, letting the students experience consequences of interactions and choices they make. Games situate players in particular literacy practices associated with the identities being played, immersing them in peculiar vocabularies and social customs; often these literacy practices are associated with real-world professional domains, or are consistent within the fantasy. Games prepare players to deal with complex electronic environments, to negotiate and handle data in multiple formats simultaneously, to interact with images, sounds and actions, and to interact with others through electronic channels [17].

DOLE is a system concept, which can be implemented as a web based online game where users log onto the website and play/learn against an artificial intelligence (A.I.) engine. For example, players think of an animal, vegetable, mineral, or other object and DOLE has to guess which term (word) the player is thinking and vice versa. The resulting system can be used anywhere and anytime. It is fun harnessing with edutainment and game learning style. It can practice the way of learner thinking and can assess skills, knowledge, and thinking of learners. Some advantages of DOLE are described as follows:

DOLE is adaptable (learns and adapts).

- It allows users to customize the game interface.

- It works as a stand-alone application.

- It can be provided via a Web Interface.

DOLE is scalable; the knowledge base can be tailored to fit various game platforms.

- It can be adapted for mobile applications.

- It handles multiple Web servers.

- It is designed to host thousands of simultaneous users.

The software development of the user interface can be carried out using rapid prototyping (for an overview of the various rapid prototyping paradigms for the implementation of user interfaces see [18]).

The system is separated into 2 parts of object learning: 1) the user thinks of an object and the system poses questions, which the user has to answer correctly; 2) the system chooses an object and lets the user ask questions about it, which the system will answer correctly. Framework 1 is described in the following.

\section{A. Framework 1}

The first framework is designed using Artificial Intelligence and an inference engine with rule base forward and backward chaining. This framework can work as follows (Fig. 2):

- Manage knowledge about things/objects, e.g. fruit, animals.

- $\quad$ Provide yes/no questions for learners.

- Search and ask reasonable questions and lead them to the right direction.

- Display questions that learners have been answered already in the session.

- Guess the answer of a thing/object that the learner is thinking of Suggest answers for each question if learners are in need.

- Assess learners' style of learning, e.g. recognition, understanding, analysis.

- Give marks to student after assessment.

- Add/Edit/Delete data of objects, pictures, multimedia and knowledge related to material of learning. 


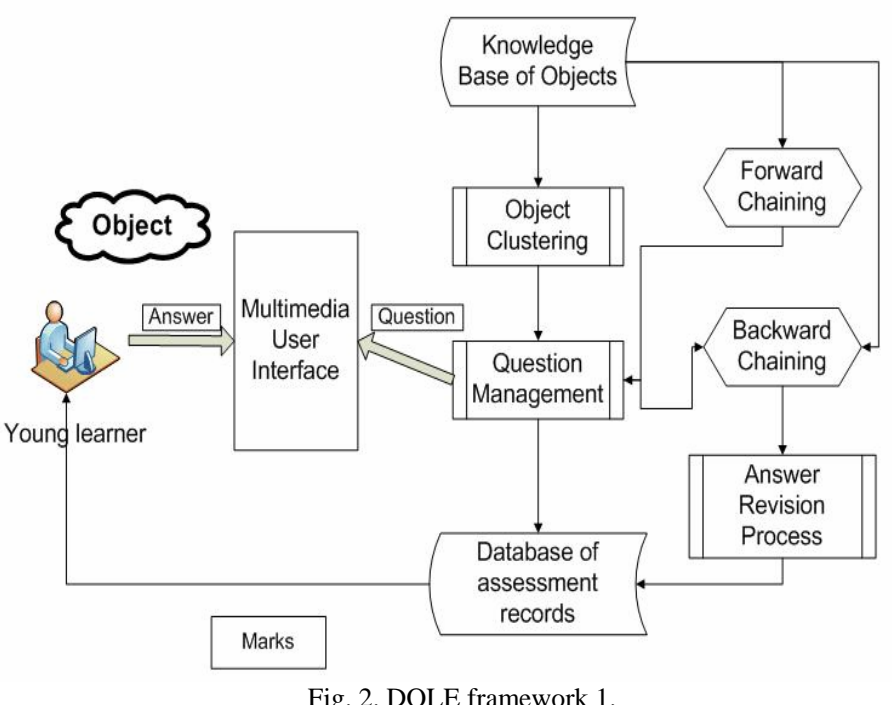

To implement this framework the following methodologies can be used:

- Clustering technique is used to group objects or things that have similar or the same characteristics, e.g. shape, taste, smell or color.

- Inference engine tools: forward chaining (data driven) is used for finding the answer of a thing or object that the user is thinking of while using the system. The tool considers/examines all information and data from the answers provided by learners, e.g., after learners choose things/objects that they want to learn and revise such as fruit then the system asks learners about shape, taste, smell, etc. of fruit. The learners have to provide correct answers as yes or no, so that the system can get back with other questions to follow by previous learner answers and can try to guess the answer.

- Backward chaining is used to recheck and trace the answers to the questions, e.g. the answer is elephant (animal section) then the system recheck all questions and answers that learners provide such as answering yes for 4 legs, big size, has trunk and tusk etc. From this, the learners can get full marks if they provide all correct answers to questions that system has generated and less mark if they answered incorrectly. There will be no more than 20 questions in each assessment.

\section{B. Framework 2}

The second framework is developed using specific name matching algorithms for matching words. This framework can work as follows (Fig. 3). Firstly, a learning and assessment domain is specified by the system, from which the objects are chosen randomly, for example fruit, vegetables, or animals. The system now allocates the properties of this object and prepares for the answering task. After that, the learner poses the questions to the system to find out the correct object. With each question the assessment part of the system evaluates the value of the question for the overall investigation process. This evaluation is based on the time used for posing questions, the number of questions until the correct answer, and so on. Should the learner misspell or mistype a keyword, the system can try to find related words with the help of the allocated properties of the object mentioned above and a word matching algorithm that compares them and their synonyms with the misspelled word. Having found the most similar match the system will reply with a question to confirm the match and provide further yes/no answers.

The user interface can display all interactions (questions and answers by both partners) at any time the learner wants them to review to find the correct answer, i.e. the object that the system is thinking of. From the questioning process and its development of finding the solution the assessment part of the system can mark the learner's comprehension, skill and knowledge. If the learners need only a few questions to find the correct solution, they get higher marks.

Parts of the concept of DOLE framework 2 are clustering and word matching techniques as outlined in the following.

Clustering is a technique used to classify similar objects into collections using criteria based on similarity, e.g. similar characteristics or similar properties. A partitioning approach can be taken to manage grouping, which results in a division of the object set into groups (classes, clusters) well separated in the feature space. The groups can be regarded as relatively "homogeneous" and labeled with properties (characteristics), so that they can be investigated separately. In DOLE, for example, the clustering technique will be used to group fruits that have similar or the same characteristics, e.g. shape, taste, smell or color. In DOLE (1) properties/characteristics (e.g., kind, shape, color, taste, smell, etc) are sorted and then related by classification; clustering stores any types of objects and some related properties and characteristics, (2) it helps the users to pose useful questions that the system has to answer, (3) it supplies fast access to required information.

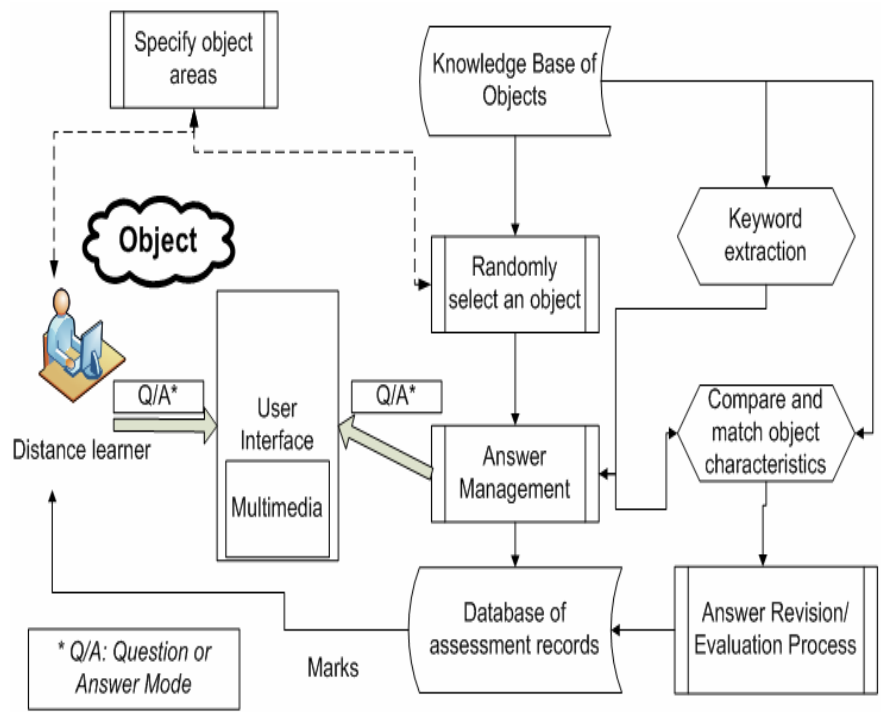

Fig. 3. DOLE framework 2. 
Word matching is used to match keywords of object characteristics in the knowledge base with words from learner's questions. Word matching can deal with wrong spellings/typing from learners as well as with relating terms/keywords to respond to those spellings correctly. Example: the learner types "grene", the system is not able to find a correct instance of this keyword and will find the nearest match with the help specific name matching algorithms as described in [19], [20], [21].

\section{CONCLUSIONS AND FURTHER WORK}

This research has led to a concept for a Distance Object Learning and Evaluation (DOLE) system, which comprises an appropriate user interface, a domain specific ontology, and a neural network for intelligent questioning and answering. A decision tree will be used to automatically arrange and provide the questions and answers.

The framework has its strengths in case of summative assessments, which are related to the learning of concepts shared as common knowledge in the native or in a foreign language. The system can be used as a tool for guided learning, assessment and self-assessment as well.

A more advanced way to enhance DOLE is to incorporate a part for the automatic interpretation of facial expressions during the assessment process. This would add to and give a richer picture of the assessment results.

Another area of further work is the recommendation of further studies and the outline of an individual study plan for the student that has been assessed and incorporating the assessment session into an e-portfolio of learning, which is an "electronically-based portfolio, i.e. a file store and information management system which is modeled on the working method used for paper portfolios, but which takes advantage of the capabilities of ICT, notably allowing earners to store digital artifacts and streamlining the process of review and moderation for learners, tutors, moderators and verifiers” [22].

\section{REFERENCES}

[1] W. Huitt. A transactional model of the teaching/learning process. Educational Psychology Interactive”, Valdosta, GA: Valdosta State University, 2003. Available from http://chiron.valdosta.edu/whuitt/materials/tchlrnmd.html.

[2] D. Brethower, K. S. Pfeiffer. Performance-Based Instruction, includes a Microsoft Word diskette: Linking Training to Business Results. 1998.

[3] J. Johnson, R. Fiene, J. Keat, H. Darling, D. Pratt, J. Iutcovich. Mastering course content and learner satisfaction in early childhood education: A comparison of regular classroom instruction with three variations of internet delivery. Journal of Early Childhood Teacher Education, vol 22, no 4, pp 267 - 274, 2001.

[4] M. Scriven. The Methodology of Evaluation. In: R. Tyler, R. Gagne, \& M. Scriven, Perspectives of Curriculum Evaluation, Chicago: Rand McNally, pp.39-83, 1967.
[5] M. Q. Patton. Paradigms and Pragmatism. In: D. M. Fetterman (ed), Qualitative Approaches to Evaluation in Education: The Silent Scientific Revolution, New York: Praeger, 1998.

[6] User-Friendly Handbook for Mixed Method Evaluations. Edited by Joy Frechtling, Laure Sharp, Westat August 1997. Available at http://www.ehr.nsf.gov/EHR/REC/pubs/NSF97-153/START.HTM

[7] A. Koohang and K. Harman. Learning Objects and Instructional Design. Informing Science, 2007.

[8] D. R. Rehak, R. Mason. Keeping the learning in learning objects, in Littlejohn. Reusing online resources: a sustainable approach to $e$ Learning, Kogan Page, London, pp.22-30, 2003.

[9] B. Caudill and D. Banks. Instructional Designer's Pocket Guide to SCORM (Paperback). JCA Solutions, First Edition edition (August 1, 2006).

[10] Learning Technology Standards Committee: IEEE Standard for Learning Object Metadata. IEEE Standard 1484.12.1, Institute of Electrical and Electronics Engineers, New York, 2002. (draft), available online http://ltsc.ieee.org/wg12/files/LOM_1484_12_1_v1_Final_Draft.pdf

[11] C. Snae and M. Brueckner. Web Based E-Learning Framework for Thai Learning Environment. In: Proceedings of International Conference eLearning 2006: Learning Theories vs Technologies, Bangkok, 14-16 December, 2006.

[12] C. Snae and M. Brueckner. Ontology-Driven E-Learning System Based on Roles and Activities for Thai Learning Environment. Interdisciplinary Journal of Knowledge and Learning, Vol. 3, pp 1-17, 2007.

[13] R. P. Donaldson and M. A. Haggstrom. Changing Language Education Through Call (Routledge Studies in Computer Assisted Language Learning). Routledge, 2006.

[14] R. Aust and R. Isaacson. Designing and Evaluating User Interfaces for eLearning.In: G. Richards (Ed.), Proceedings of World Conference on E-Learning in Corporate, Government, Healthcare, and Higher Education, Chesapeake, VA: AACE, pp 1195-1202, 2005. Available online from:

http://elearndesign.org/papers/eLearn2005_Aust.pdf (viewed Nov. 10, 2007).

[15] S. Harri-Augstein and L. F. Thomas. Learning conversations. London: Routledge, 1991.

[16] M. Prensky, Digital Game-based Learning, New York, 2001.

[17] C. Snae, M. Brueckner, and W. Wongthai. E-Assessment Framework for Individual Learners. In: Proc. of International Conference on ELearning: Strategies and Edutainment, Bangkok, Thailand, 7-11 March, 2008.

[18] F. Hardtke. Rapid Prototyping for User-Friendly and Useful Human Machine Interfaces. In: Proceedings of SIMTECT 2001, Simulation Industry Association of Australia, Canberra, Australia. Available online http://www.siaa.asn.au/get/2395363450.pdf (viewed Nov 3, 2007)

[19] C. Snae. A Comparison and Analysis of Name Matching Algorithms. International Journal of Applied Science. Engineering and Technology, Vol 4 no. 1, pp. 252-257, 2007.

[20] C. Snae, K. Namahoot and M. Brueckner. MetaSound: A New Phonetic Based Name Matching Algorithm for Thai Naming System. In: Proc. of International Conference on Engineering, Applied Science and Technology (ICEAST 2007), 21-23 November, Bangkok, Thailand, 2007.

[21] C. Snae and M. Brueckner. A Semantic Web Integrated Searching System for Local Organizations with Thai Soundex. In: 4th International Joint Conference on Computer Science and Engineering (JCSSE 2007) 2-4 May, Khon Kean, 2007.

[22] JISC, E-assessment (Glossary), 2006. Available from: http://www.jisc.ac.uk/uploaded_documents/eAssess-GlossaryExtended-v1-01.pdf (access Nov. 3, 2007) 